\title{
Open Innovation in SMEs: From Closed Boundaries to Networked Paradigm
}

\author{
Hakikur Rahman and Isabel Ramos \\ University of Minho, Guimaraes, Braga, Portugal \\ hakik@dsi.uminho.pt; iramos@dsi.uminho.pt
}

\begin{abstract}
Successful innovation is a key to business growth. In the realm of technological development, innovation processes have been transformed into various forms, like open innovation, crowdsourcing innovation, or collaborative innovation. This research would like to focus on open innovation processes to reach out to the common stakeholders in the entrepreneurship system through small and medium enterprises. It has been observed that to provide innovative services or products to the outer periphery of the customer chain, SMEs play an important role. Hence, focusing innovation for SMEs would lead to a newer dimension of innovation research for better business and economic growth. The research emphasizes on various open innovation strategies for SMEs at the outset by focusing transformation of innovation processes from a closed boundary leading to a networked paradigm, try to provide some overview on a few innovation strategies, and develop a business model. The paper also discusses about some challenges and barriers that SMEs are facing in implementing open innovation strategies. Before conclusion, it put forwards issues of future research.
\end{abstract}

Keywords: innovation, open innovation, crowdsourcing innovation, collaborative innovation, SME.

\section{Introduction}

Innovation, in general sense may be seen as a process of designing, developing and implementing a novel product or service to improve economic, physical and logical parameters in the process. Open innovation, on the other hand, incorporates joint efforts from in-house capabilities and possible outsourcing or combination of several input paths during the product or service development.

However, innovation is not just any sort of change in an entity. It focuses on qualitative changes, and especially targeted to enhance knowledge gain that would lead to economic gain. It is not just adapting someone's novelties, but it creates something of its own as a new, at least not existed in exactly in such form before. Innovation may incorporate product specialization, or targeted com-

Material published as part of this publication, either on-line or in print, is copyrighted by the Informing Science Institute. Permission to make digital or paper copy of part or all of these works for personal or classroom use is granted without fee provided that the copies are not made or distributed for profit or commercial advantage AND that copies 1) bear this notice in full and 2) give the full citation on the first page. It is permissible to abstract these works so long as credit is given. To copy in all other cases or to republish or to post on a server or to redistribute to lists requires specific permission and payment of a fee. Contact 0HPublisher@InformingScience.org to request redistribution permission. mercialization, or an invention deliberately attempting to enhance the product value.

There could be product, service, process or technological innovation at the organizational level, or organizations at the grass roots, and be it fostered collaboratively. In the paradigm of opening the innovation process adaptable to the global environment to be termed as open 
innovation by incorporating knowledge flux from inside or outside (crowdsourcing), leading to unilateral development or outsourcing incorporates several stages of development (see Figure-1). It could follow any of these separate channels, or accommodate more than one channel to produce an innovative product. However, in Figure-1 authors are emphasizing on incorporation of input fluxes in the first three stages accommodating crowdsourcing to improve the business process, and through outsourcing at stage four the production and marketing chain can be improved further.

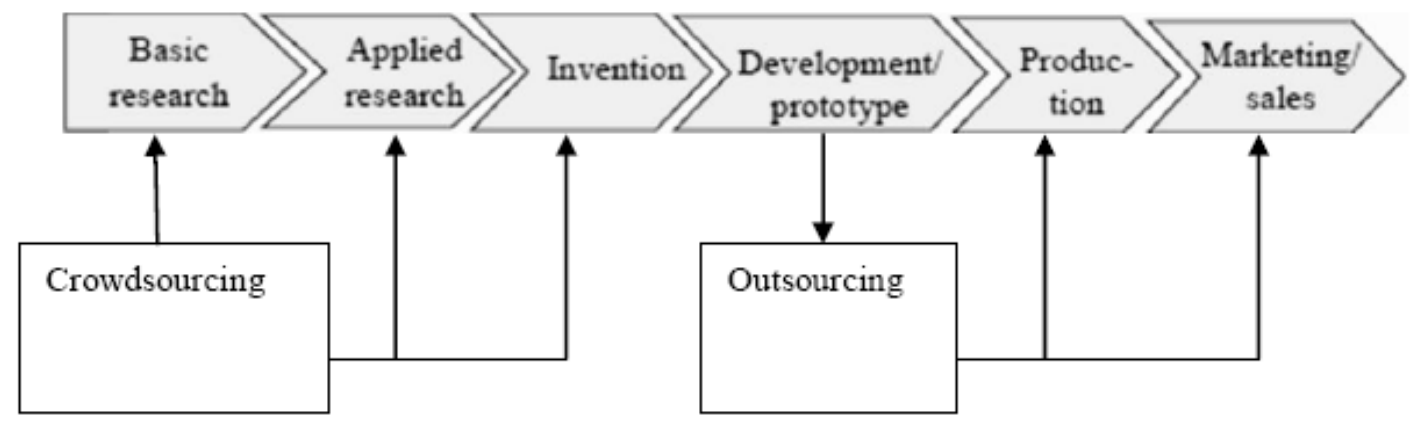

Figure-1: Open Innovation process

(Adapted from Christensen, 2007; Lichtenthaler \& Ernst, 2009; Authors)

In the context of open innovation (OI), it is seen as utilization of inbound and outbound knowledge flows converting to economic values, and acceleration of product development and marketing accumulated ideas leading to added value chain (De Jong, Vanhaverbeke, Kalvet \& Ches-

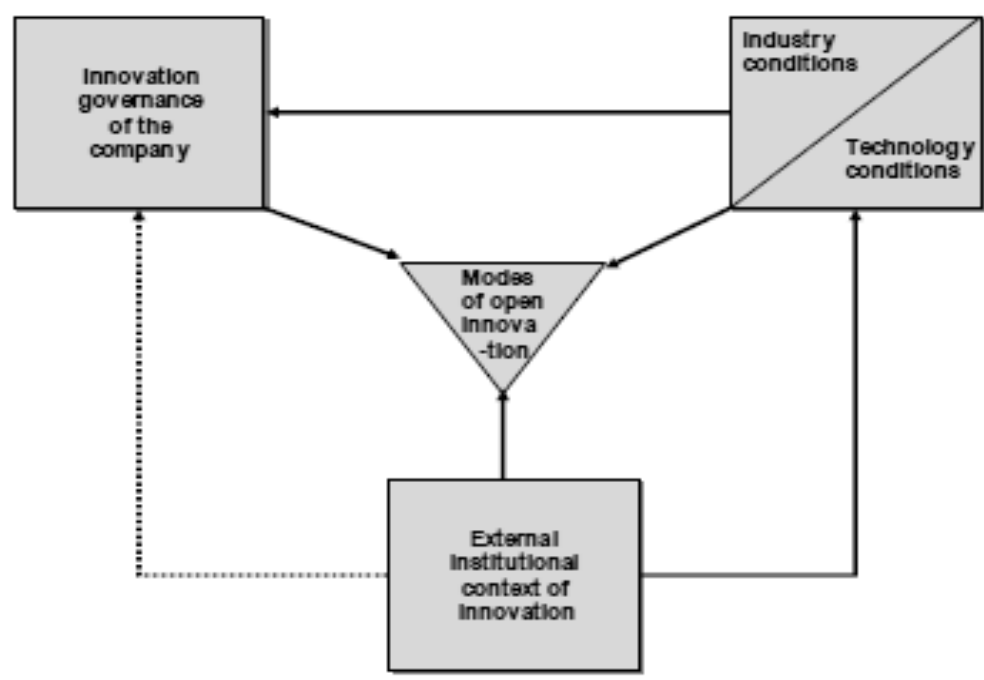

Figure-2: Factors effecting open innovation (Adopted from Beije, 2005). 
brough, 2008). Diversified factors affect the open innovation process, in addition to an organization's inherent entity. As illustrated in Figure-2, it incorporates management, governance, skills, technologies and policy matters. It also integrates relationship of open innovation factors with other interrelated organizations, institutions and agencies. However, the fact is that in the arena of open innovation, much has not been researched in these aspects. Above all, at the policy making level, not enough work have been carried out to facilitate familiarization of positive aspects and impact of open innovation to the policy initiators, especially at the socio-economic strata. Furthermore, the role of government remains unchartered in many facets in the decision making process of open innovation at the national level.

Till to date, most studies have examined open innovation at the organizational level, basically for two reasons. Firstly, innovation is traditionally conceived as the outcome of deliberate actions of a single entrepreneur, and thus R\&D competition has also been styled as an innovation race between two or more entrepreneurs. Secondly, the value of a technological invention is realized only through a business model of the enterprise (Chesbrough \& Rosenbloom, 2002). While it is very natural that the business model may easily spill over the boundaries of an enterprise or even an industry (West, Vanhaverbeke, \& Chesbrough, 2006).

Most of the researches in open innovation remain restricted towards targeting common stakeholders through major global entrepreneurs or their alliances. In addition, a few of those global business houses are controlling the entire market or system of open innovation development through process modification and or diversification of resources. Despite immense potentiality to reach out the stakeholders at the grass roots through open ended demand, diversity of product variation, and scale of economic capacity major contemporary researches are confined towards generic pattern-oriented clients.

By far, the small and medium enterprises (SMEs ${ }^{i}$ ) who always deal with the clients at the grass roots the most and they have to satisfy the client base, though seldom they produce the product. Moreover, despite the globalization that offers unprecedented opportunities and challenges for SMEs, but seemingly they are thinking of mere survival in the context of global economy, marketing, value promotion, job creation and expansion (CSR Europe, 2008a, 2008b). SMEs in Europe comprises of about $23 \mathrm{M} €$ investment market that account for $99 \%$ of all businesses and represent $2 / 3^{\text {rd }}$ of the total employment (Renaud, 2008). However, in spite of being key contributor to the global economy accounting for approximately $50 \%$ of local and national GDP, $30 \%$ of export and $10 \%$ of FDI (This refers to firms in the formal sector only.) most of the SMEs communities are lagging behind promoting their products at the national level, and at the global level (OECD, 2006).

This research argues that the time has come to transform the process of innovation system (through organized deregulation, wider knowledge distribution, focused training, and capacity development) to put SMEs at the heart of the technology transfers as they represent a privileged source for the innovations in a competitive context in which large companies prefer to concentrate on their core competencies. So, SMEs play an important role and distinct part in the innovative activity whereas many large firms are acting as just a systems integrator. However, the challenge remains, particularly as delicate as before, because SMEs do not exists in this global environment by themselves, they require stronghold interoperability to larger entrepreneurs for better opportunities, to intermediaries for improving their capacities, and to the grass roots clients for offering better services. Hence, there are scope of promoting OI to reach out the grass roots, not only through the SMEs, but also through a combination of SMEs, agencies of corporate entrepreneurs, research centres, team of university researchers, and other catalytic factors.

This research will try to focus on innovation strategies initiating from closed innovation to open innovation, from $\mathrm{R} \& \mathrm{D}$ to $\mathrm{C} \& \mathrm{D}$, from competition to cooperation leading to networked innovation 
(networked paradigm) improvising challenges faced by SMEs on the way of establishing collaborative innovation. It will categorize various aspects of open innovation in terms of reaching out the broad based clientele through SMEs, synthesize various operational models that are found in the contemporary arena, and try to framework a sustainable business model. The research will outline a discourse of SMEs within the OI models by establishing a network of SMEs, agents of corporate business groups, and team of university researchers targeting client base at the grass roots through the process of open innovation. Before conclusion, the paper will hint on a few aspects of future research.

\section{Background}

Innovation, by definition could be termed as the creation, development and implementation of a new product, process or service, aiming at improving efficiency, effectiveness or competitive advantage. The term may apply to products, services, manufacturing processes, managerial processes or the design of an organization. It is most often viewed at a product or process level, where product innovation satisfies a customer's needs and process innovation improves efficiency and effectiveness of the organization. Innovation links to creativity and the creation of new ideas, and involves taking those new ideas and turning them into reality through invention, research and new product development (Digital Strategy, n.d.). Furthermore, innovation can be seen as the process that translates knowledge into economic growth and social well-being. It encompasses a series of scientific, technological, organizational, economic and commercial activities. Researches in the context of innovation are targeted towards one of these activities and may be carried out at different phases of the innovative process (Australian Research Council, n.d.).

Innovation could be driven by technology, supply, demand, process, design, value, sustainability, economy, culture, or regulation. The product may range from basic health support, inter-personal communications, equipment or accessories of specific nature, or supply driven items, as such targeting electronic and communication products, fashion industries, household items, constructions, or items of creative in nature. Moreover, innovation is the nimbleness to adapt with the dynamic trend of the global market, and especially capable of growing, adjusting, modifying, or innovating at the same speed or faster than the ambient economic environment (Clark \& Gottfredson, 2008). In addition to these, the organization must have the competency to undertake the challenges of today, else today's problems will accumulate tomorrow to become more complex task that may lead to become insurmountable (West, Vanhaverbeke \& Chesbrough, 2006).

Open Innovation (Wikipedia, n.d.), a term recently added to the industries and organizations to promote open ended ideas, thoughts, processes, and researches to improve the product development, provide better services to the clients, increase efficiency and enhance value-addition. In terms of process dynamics, it incorporates accumulation of ideas, knowledge, licenses, intellectual properties, patents, and inventions (through licensing, joint ventures, spin-offs); and in terms of concept dynamics, user innovation, market innovation, cumulative innovation and distributed innovation.

Open innovation emerges on issues like, in the diverse world of widely distributed knowledge, solitary enterprises cannot afford (economically and organizationally) to rely entirely on their own research and resources, but may instead collaborate, buy, lease-out or license processes or inventions (patents, intellectual properties) from other companies, organizations or institutions. In addition, internal inventions that are not being used in a company's business process should be taken outside the company (through licensing, joint ventures, spin-offs). Currently, many companies are promoting open innovation and among them IBM, InnoCentive, InnovationXchange, Nerac, NineSigma, Nokia, Procter \& Gamble, and Yet2.com (Wikipedia, n.d.) are widely renowned. 
For sake of this research, literature review will be limited to only challenges that are being faced by SMEs on the way of establishing innovation, development of a sustainable business model, and inclusion of SMEs into a possible discourse within the process. However, before referring to the issues of challenges, a few strategies on open innovation towards the transformation process will be discussed next.

\section{Strategies}

Despite being a relatively new field as it has been introduced very recently, many of the concurrent researchers and organizations are active in making progressive researches on open innovation, and therefore, several strategies on OI prevail. Focused to open innovation for SMEs, this research entails a few of them those eventually lead to the proposed strategy of this research, which is networked and collaborative innovation.

\section{From ‘Closed Innovation' to 'Open Innovation'}

Closed innovation refers to processes that restrict the use of internal knowledge solely within a company and make little or no use of external knowledge (Wikipedia, n.d.). On the other hand, open innovation assumes that enterprises can and should use external ideas as well as internal ideas, and internal and external paths to market (concurrently, and successively) to discover and realize innovative opportunities. The open innovation model can be compared with the conventional, closed model in which enterprises generate, develop and market their own ideas, usually prepared in an internal R\&D department (see Figure-3). This closed model has become outdated due to increased mobility of workers, better education, growing presence of venture capital, increasingly shortened product life cycles, growing competition, globalization of economy, improved use of information technology, and wide availability of knowledge from multiple sources. The better portion of the fact is that, in the open innovation model, enterprises can still initiate and nurture innovations within the boundaries of their organizations, but at the same time they may also draw on alternative pathways to bring ideas to the market and to benefit from external knowledge (De Jong et al., 2008).

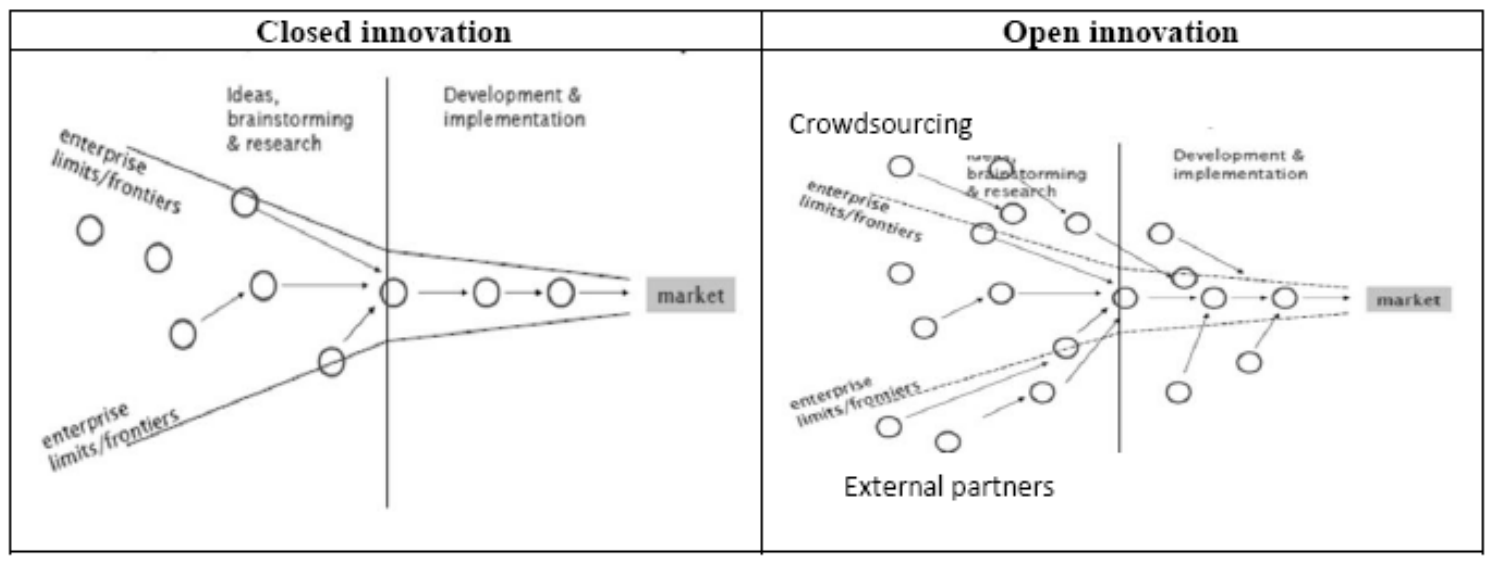

Figure-3: Comparison of open innovation with closed innovation (Adapted from Höllmüller, 2008; Authors)

\section{From 'Research and Development' to 'Connect and Develop'}

Along the progress of development with concept of open innovation, majority of the entrepreneurs are shifting towards connecting their own R\&D department to the outside of their bounda- 
ries and develop their products or services. This is termed as shifting from research and development (R\&D) to connect and develop (C\&D). As stated by Huston \& Sakkab (2006) that, two senior executives from Procter \& Gamble have studied outside sources of innovation, and estimated that for every $\mathrm{P} \& \mathrm{G}$ researcher there were 200 scientists or engineers elsewhere in the world (around a total of 1.5 million people) who were just as good as talents the company could potentially use. But tapping into the creative thinking of potential inventors and others on the outside would require massive operational changes. Therefore, they needed to move the company's attitude from resistance to innovations "not invented here" to enthusiasm for those "proudly found elsewhere"; and needed to change how it was defined, and perceived, their R\&D organization from 7,500 people inside to 7,500 plus 1.5 million outside, with a permeable boundary between them.

Huston \& Sakkab (2006) further revealed that by 2006, more than 35 percent of their new products in market had elements that originated from outside P\&G, up from about 15 percent in 2000. And 45 percent of the initiatives in their product development portfolio had key elements that were discovered externally. Through connect and develop strategy, along with improvements in other aspects of innovation related to production cost, design, and marketing their R\&D productivity has increased by nearly 60 percent. Their innovation success rate has been raised to more than doubled, while the cost of innovation has fallen. R\&D investment as a percentage of sales was down from 4.8 percent in 2000 to 3.4 percent in 2006. And, during 2004-2006, they launched more than 100 new products for which some aspect of execution came from outside the company. Furthermore, five years after the company's stock collapse in 2000, they doubled their share price with a portfolio of twenty-two billion-dollar brands.

As a case, $P \& G$ is being mentioned here, though hardly it can be ranked as SME. Intention of this research is to look into the detail of similar operation and recommend them to a few selected SMEs during the research period. This research will select the SMEs during the second quarter of 2010 and afterwards research documentations will be prepared noting their adaptability within the proposed framework.

\section{From Competition to Cooperation}

Challenging the increasing global competition and coping the rising $\mathrm{R} \& \mathrm{D}$ costs, companies can no longer survive on their own R\&D efforts but look for new and more open modes of innovation. Nowadays, companies' innovation activities are increasingly becoming international, and they are day by day embracing strategies of collaboration, rather than competition. Most of the successful OI entrepreneurs are collaborating with external partners, whether suppliers, customers or universities, to keep ahead of the game and get new products or services to market before their competitors (De Backer, 2008).

Enterprises consider innovations as a major engine to augment their performance and to reinforce their competitive position in the market. Many firms have paid most of their management attention to an extended focus on internal efficiencies of the development process, team structures, decision making and cross functional interactions. However, as more and more entrepreneurs are bringing innovation straight to the heart of their corporate strategies, developing internal innovation capabilities is no longer adequate to gain and sustain competitive advantage. Since innovation strategies look increasingly similar and commoditized, increasing numbers of organizations are trying to further improve their innovation performance through intensifying collaboration and partnership across industry rather than competition (Chesbrough 2003, 2006; De Vrande, De Jong, Vanhaverbeke \& De Rochemont, 2008; EIRMA, 2004; Lindermann, Valcareel, Schaarschmidt \& Von Kortzfleisch, 2009). Figure 4 portrays a decade of cooperation at the international level in the area of science and technology, and Figure-5 shows cooperation strategies among SMEs at the regional level. 
In Figure-4, it is evident that cooperation in terms of patents invented in collaboration and scientific publication with foreign coauthors has increased rapidly in recent years. Similarly, Figure-5 is showing several initiatives taken at regional levels to increase cooperation among SMEs.

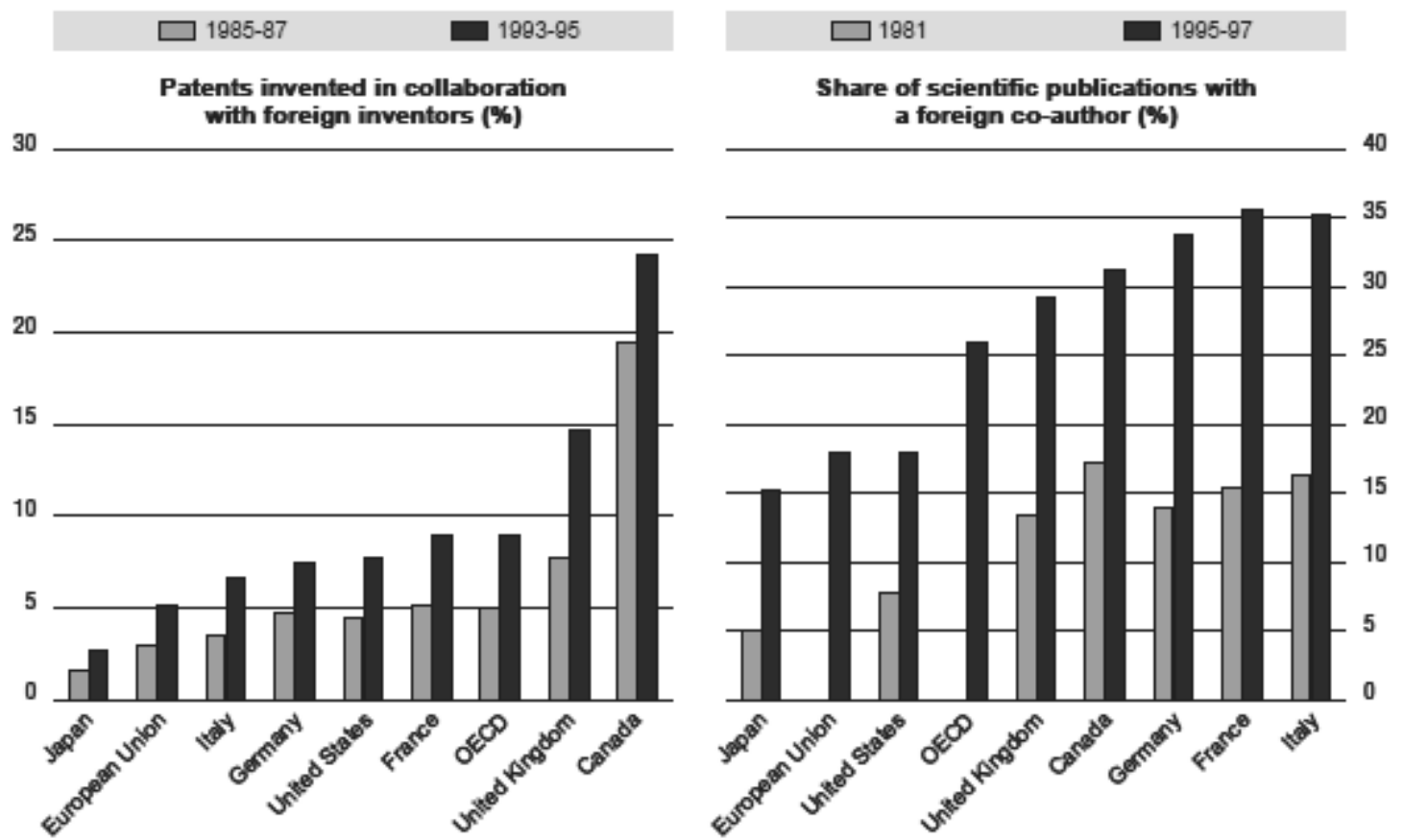

Figure-4: Cooperation in the fields of science and technology at international level (Adopted from OECD, 2000)

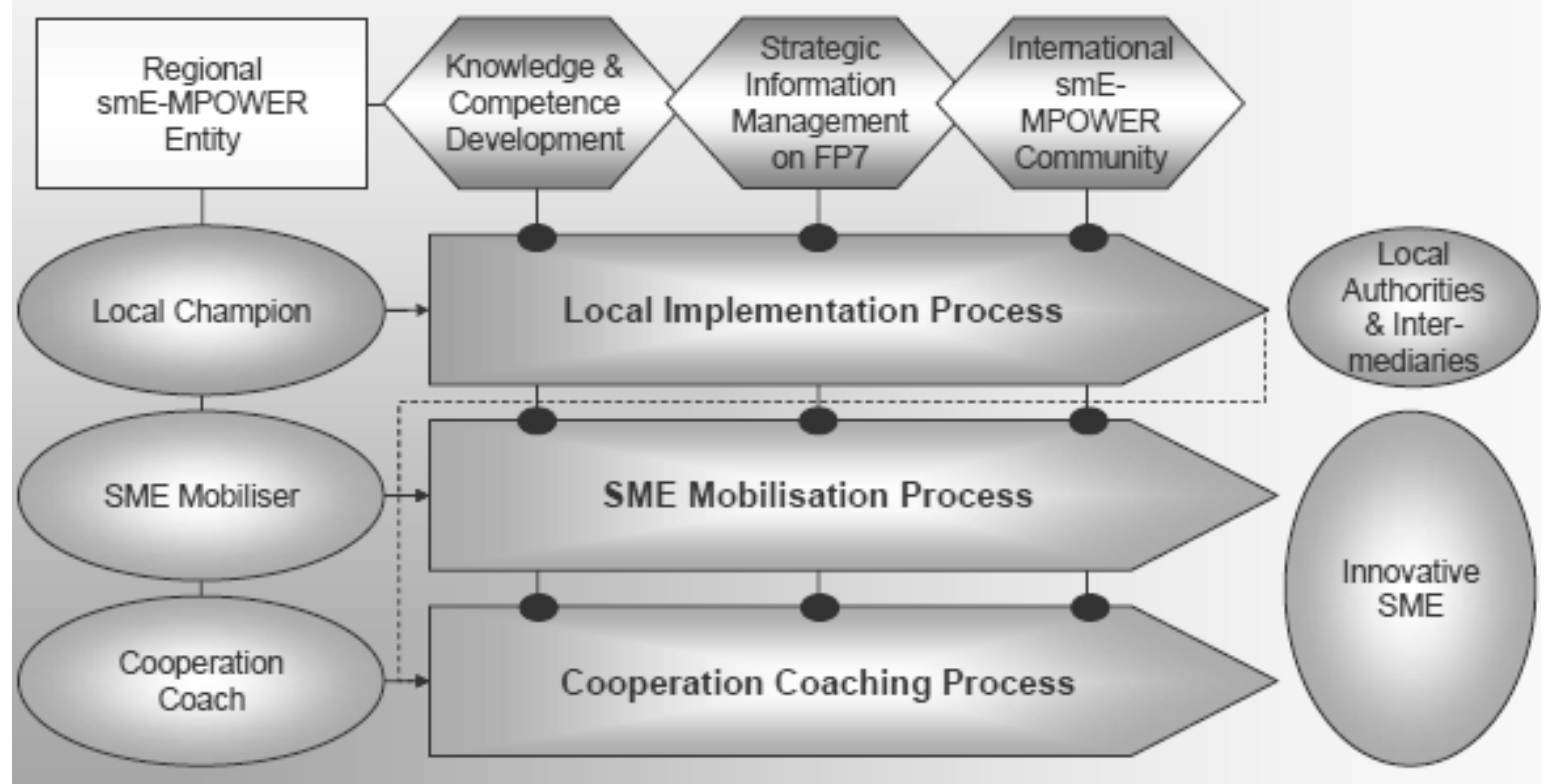

Figure-5: Cooperation among SMEs at the regional level (Adopted from Wolf, 2005)

\section{From 'closed peripheries' to 'networked paradigm'}

In this strategy, open innovation encompasses different dimensions of hypothesis ranging from in-house knowledge exploration and partnership among similar organizations to establish net- 
working among organizations, agencies and institutions. However, De Vrande et al. (2008) emphasized on two aspects. Firstly, there is the inside-out movement (or technology exploitation), in which existing technological capabilities are leveraged outside the boundaries of the firm. Secondly, there is also an outside-in movement (or technology exploration), in which external sources of innovation are used to enhance current technological developments. Hence, in a comprehensive open innovation setting, companies combine both technology exploitation and technology exploration in order to create maximum value from their technological capabilities or other competencies.

However, in order to successfully develop and commercialize new products, and achieve high innovation performance SMEs need to collaborate with external networks (Pullen, De WeerdNederhof, Groen \& Fisscher, 2008). In this aspect, one may focus on the following four approaches of open innovation, such as collective or pooled R\&D, spinouts or collaborative development, promoting products in partnerships and attracting similar actors to come forward for creating a positive ambiance through crowdsourcing (West \& Gallagher, 2006).

Furthermore, as West \& Gallagher (2006) argued that, a central concern will remain there as how to best utilize the internal R\&D capabilities of SME to maximize advantages through this form of open innovation. Those capabilities could include generation of innovations for internal commercialization similar to the traditional model; building of absorptive capacity and utilize that capacity to identify other external innovations; generation of innovations that promote value chain through external commercialization; and generation of intellectual property (IP) that may not produce direct economic benefit, but indirectly generates return through spillovers or sale of related products and services. It has been observed that successful approaches often combine a variety of strategies. Figure- 6 shows how an organization may turn from $U$ form (top-to-bottom/ up-todown management), via $\mathrm{M}$ form (multi-divisional management) to networked form (ubiquitous management) (Pullen et al., 2008).

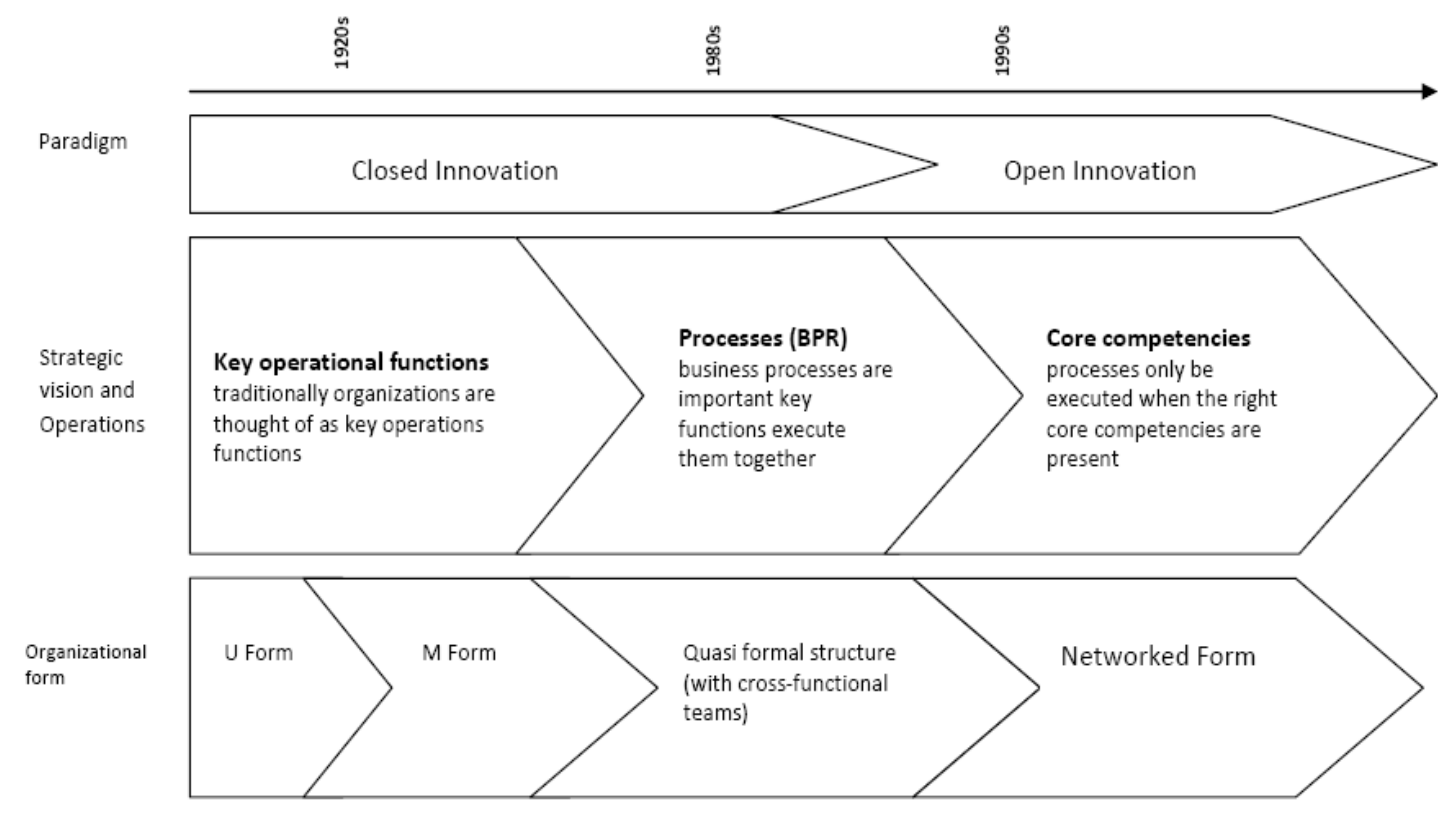

Figure-6: From closed towards open innovation (Adopted from Pullen, De Weerd-Nederhof, Groen \& Fisscher, 2008) 
Despite various strategies taken by entrepreneurs, research houses, and institutions, there remain diverse challenges in the arena of open innovation for SMEs. These could be, What drives open innovation for SMEs?; How global innovation networks have developed incorporating SMEs?; How do global innovation networks operate to promote SMEs at the grass roots?; How big are global innovation networks as compared to networks comprised of SMEs?; What are the potential challenges for framing out a global innovation networks incorporating SMEs?; and What role a national policy should take to promote SMEs in the value chain? (De Backer, 2008). The next section has been devoted to discuss more on these challenges and issues related to the promotion of open innovation for SMEs at the grass roots.

\section{Challenges}

As mentioned above, a successful open innovation strategy for SMEs should find creative ways to exploit internal innovation by incorporating external innovation into internal development, and able to motivate external actors to sustain an ongoing stream of external innovations. However, while approaching the global market, it can be observed that large industries, especially the high tech ones, are already involved in open innovation scheme, and competing each other. In terms of SMEs with high tech facilities, often generated from universities or research center, would like to maintain good links to larger organizations, rather than reaching out to the grass roots. On the contrary, SMEs at the local level, equipped with low tech facilities are loosely motivated to promote research, and may not have sufficient resources to identify their needs for innovation through appropriate market analysis, and act accordingly to a defined innovation scheme. The problem aggravates further without an appropriate and adaptive business model (West \& Gallagher, 2006).

Along this context, isolated SMEs are also in lack of adequate resources, so that they can at least take a medium term planning, if not a longer-term projection, to sensitize their demand and obtain an access to better research output. Majority of the SMEs falls under this category. To be more specific, SMEs in this category always find it difficult to enter a sustainable value chain market, as they only focus on short term market promotion; lack of even medium term demand due to mere limited resources; and lack of an authenticated contact network. Furthermore, most of the academic world is often lack vision and perspective of real life situation at the ground level while conducting researches in the field of open innovation, and therefore, question of reliability may arise. Foremost, the time frame of research output from the research team at universities may not always coincide with the actual time scale of SMEs to be ready to aggressively enter into the market at the right time and with the right product (CSR Europe, 2008b).

Furthermore, new product development always remains at the top of the agenda for both large and small- and medium sized organizations. However, compared to large firms, SMEs have a number of typical problems with regard to their innovation process, especially during the period of the development stages to the commercialization stages (Hanna \& Walsh, 2002). In those stages, they are more challenged by financial constraints, in addition to other bottlenecks such as lack of qualified personnel and low possibility to substitute relevant products in the market and sufficient fixed asset in terms of cash (Kaufmann \& Tödtling, 2002). On the other side, however, SMEs have some advantages with regard to new product development that makes them suitable as network partner, as they are usually less bureaucratic, and in general they may have greater incentives to be successful than large firms (Michael \& Palandjian, 2004). But, as the SME desires to be included in the network to achieve high innovation performance at the individual level, the question arises of how to organize new product development within the network (Pullen et al., 2008).

In addition to these, a primary factor that relates to innovation in SMEs is the vision of innovation as perceived by the top management of the firms. Sometimes they may not act as the facilitators, 
and this perception is rather difficult to measure and motivate the stakeholders (Hadjimanolis, 1999). Moreover, there are other internal barriers and external barriers to innovation for SMES (see Table-1).

Table-1: Barriers of open innovation for SMEs

(Hadjimanolis, 1999; Piatier, 1984; Rush \& Bessant, 1992)

\begin{tabular}{|c|c|c|c|c|c|}
\hline \multicolumn{3}{|c|}{ External barriers } & \multicolumn{3}{|c|}{ Internal barriers } \\
\hline Supply & Demand & Environment & Resource & $\begin{array}{l}\text { Culture/ } \\
\text { human na- } \\
\text { ture }\end{array}$ & System \\
\hline $\begin{array}{l}\text { Technological } \\
\text { information }\end{array}$ & $\begin{array}{l}\text { Customer } \\
\text { needs }\end{array}$ & $\begin{array}{l}\text { Government } \\
\text { regulations }\end{array}$ & $\begin{array}{l}\text { Lack of inter- } \\
\text { nal funds }\end{array}$ & $\begin{array}{l}\text { Attitude of } \\
\text { top man- } \\
\text { agement to } \\
\text { risk }\end{array}$ & $\begin{array}{l}\text { Out-of-date } \\
\text { accounting } \\
\text { system }\end{array}$ \\
\hline Raw materials & $\begin{array}{l}\text { Customers' } \\
\text { perception of } \\
\text { the risk of } \\
\text { innovation }\end{array}$ & $\begin{array}{l}\text { Anti-trust } \\
\text { measures }\end{array}$ & $\begin{array}{l}\text { Technical } \\
\text { expertise }\end{array}$ & $\begin{array}{l}\text { Employee } \\
\text { resistance to } \\
\text { innovation }\end{array}$ & \\
\hline \multirow[t]{2}{*}{ Finance } & $\begin{array}{l}\text { Domestic } \\
\text { market limita- } \\
\text { tion }\end{array}$ & Policy actions & $\begin{array}{l}\text { Management } \\
\text { time }\end{array}$ & & \\
\hline & $\begin{array}{l}\text { International } \\
\text { market limita- } \\
\text { tion }\end{array}$ & & & & \\
\hline
\end{tabular}

Inclusive of above challenges, open innovation for SMEs, deserves further emphasize in resolving issues, like sales, licenses, cash flow, and trust in business relationship; to fulfill the grass roots clientele base by understanding their demand; to develop a transparent business process that add value to it; and to combine knowledge and technology for building a pipeline of opportunities, enabling a broad-based B2B networking through sustainable organic growth. Next, the paper will discuss on developing a sustainable business model justifying the needs of SMEs to reach out to the grass roots.

\section{Development of the Business Model}

A business model may be seen as the totality of how a company selects its clients, defines and differentiates its responses; classifies those tasks it will perform itself and those it will outsource; configures its resources, goes to market, creates utility for clients; and get hold of profits. It is the entire system for delivering utility to clients and gaining a profit from that activity (Pourdehnad, 2007). Figure-7 shows a relationship diagram with the various actors or stakeholders involved in a business model. This evidently envisage the clear bonding among visible groups of stakeholders among the business communities. 


\section{Contextual Environment}

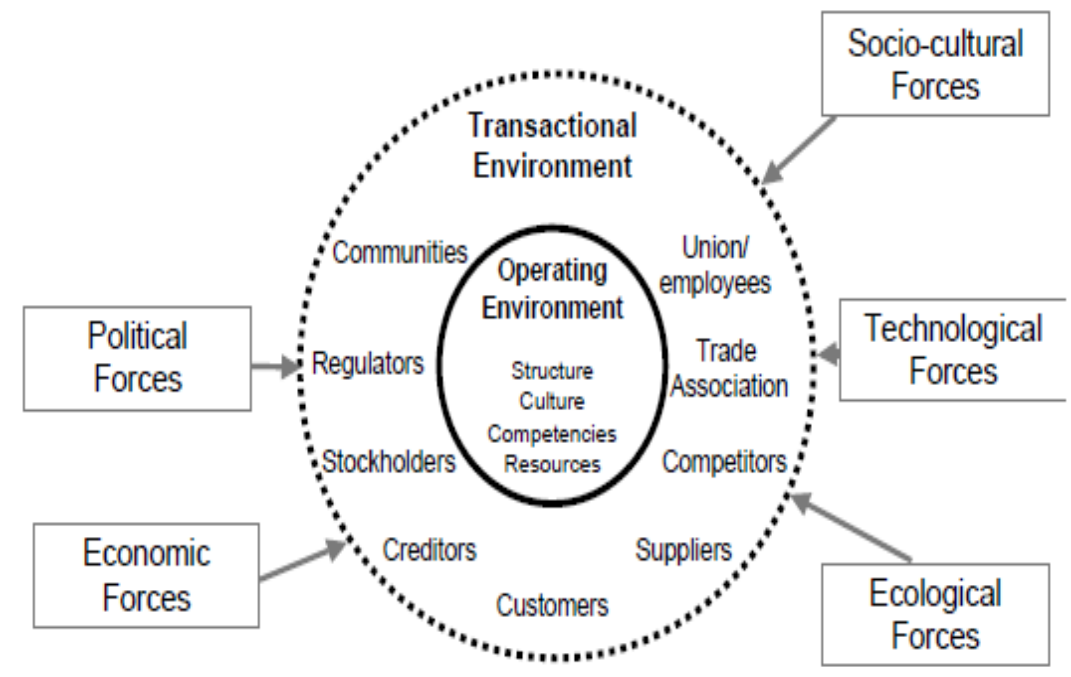

Figure-7: Relationship with the stakeholders in a business model

(Adopted from Pourdehnad, 2007)

Triple Helix Model (see Figure-8) is another highly discussing model in this arena. According to this model, a spiral of innovation involves government, university, and industry in multiple reciprocal relationships, to create a flexible overlapping innovation system (CSR Europe, 2008b).

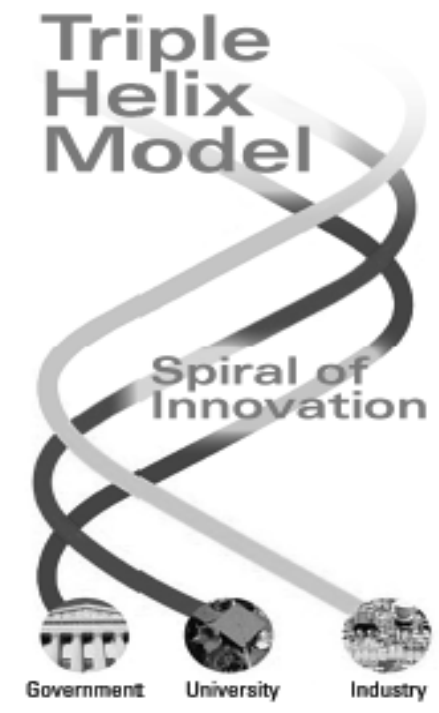

Figure-8: The triple helix model (Adopted from CSR Europe, 2008b)

This research would like to point out to another business model that may be utilized in SMEs OI process, which has been developed incorporating mixed approach (Shorthouse, 2008). Figure-9 shows a mixed approach (closed and open innovation) business model. Shorthouse (2008) has adopted a joint effort to reach the niche market through using both closed and open innovation business model. 


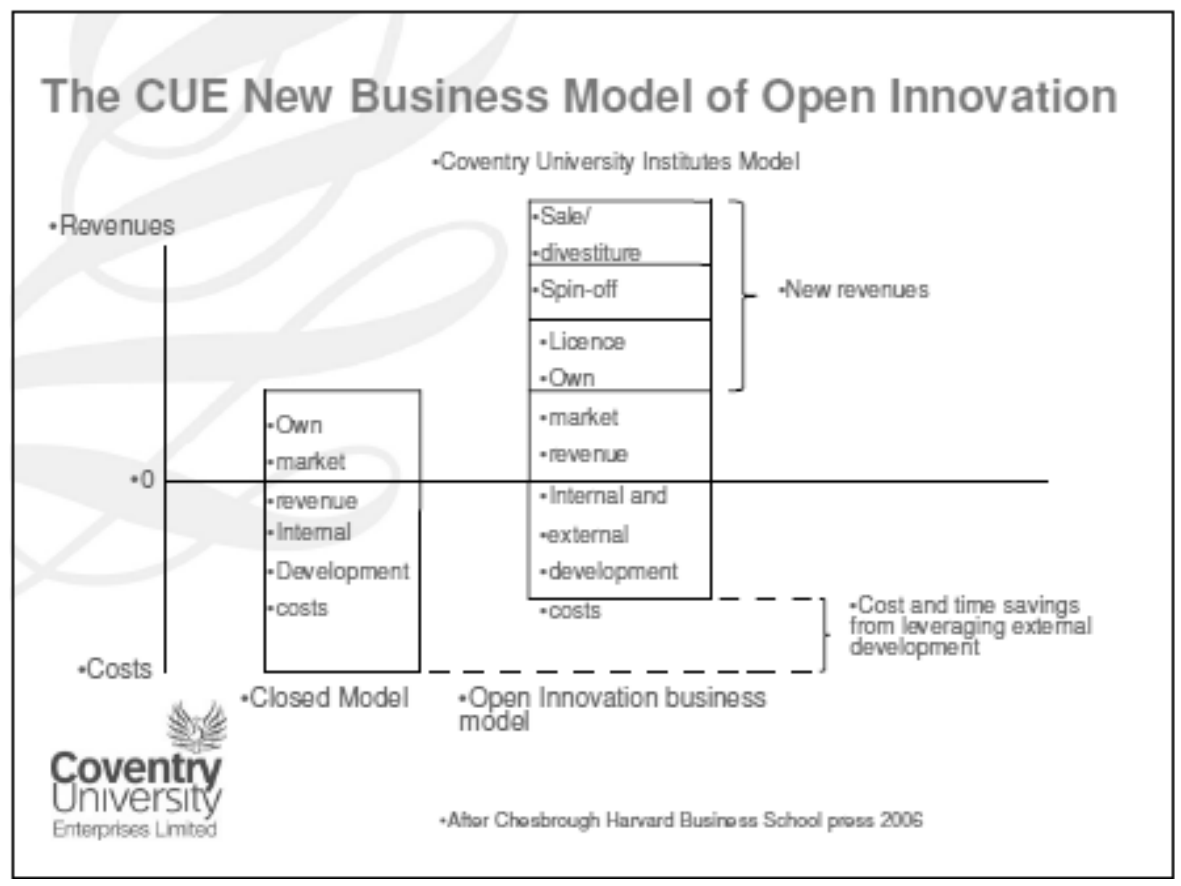

Figure-9: A mixed approach business model (Adopted from Shorthouse, 2008)

However, to attain a sustainable business model in SMEs open innovation, one needs to follow the flowchart indicated below:

\section{Educate and raise SME awareness}

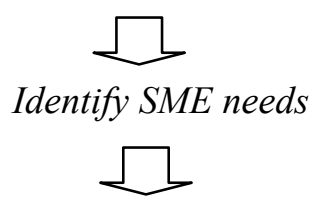

Facilitate interactions between SMEs \& Research Orgs

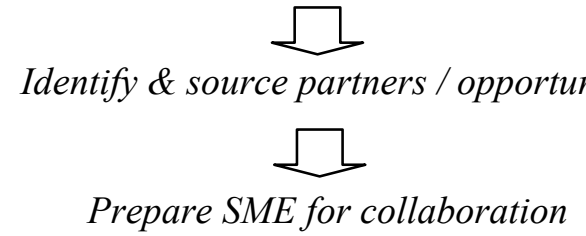


Furthermore, a sustainable business model should also follow to:

Introduce both the closed and open innovation paradigms as optimized

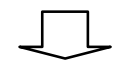

Facilitate drivers of changes in the innovation process

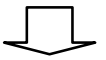

Undo the possibilities of open innovation paradigm

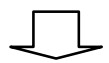

Obtain better understanding of niche markets

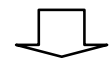

Properly handle challenges of innovation management

The business model should incorporate inclusion of SMEs inclusive in the following dimension: (See Figure 10)

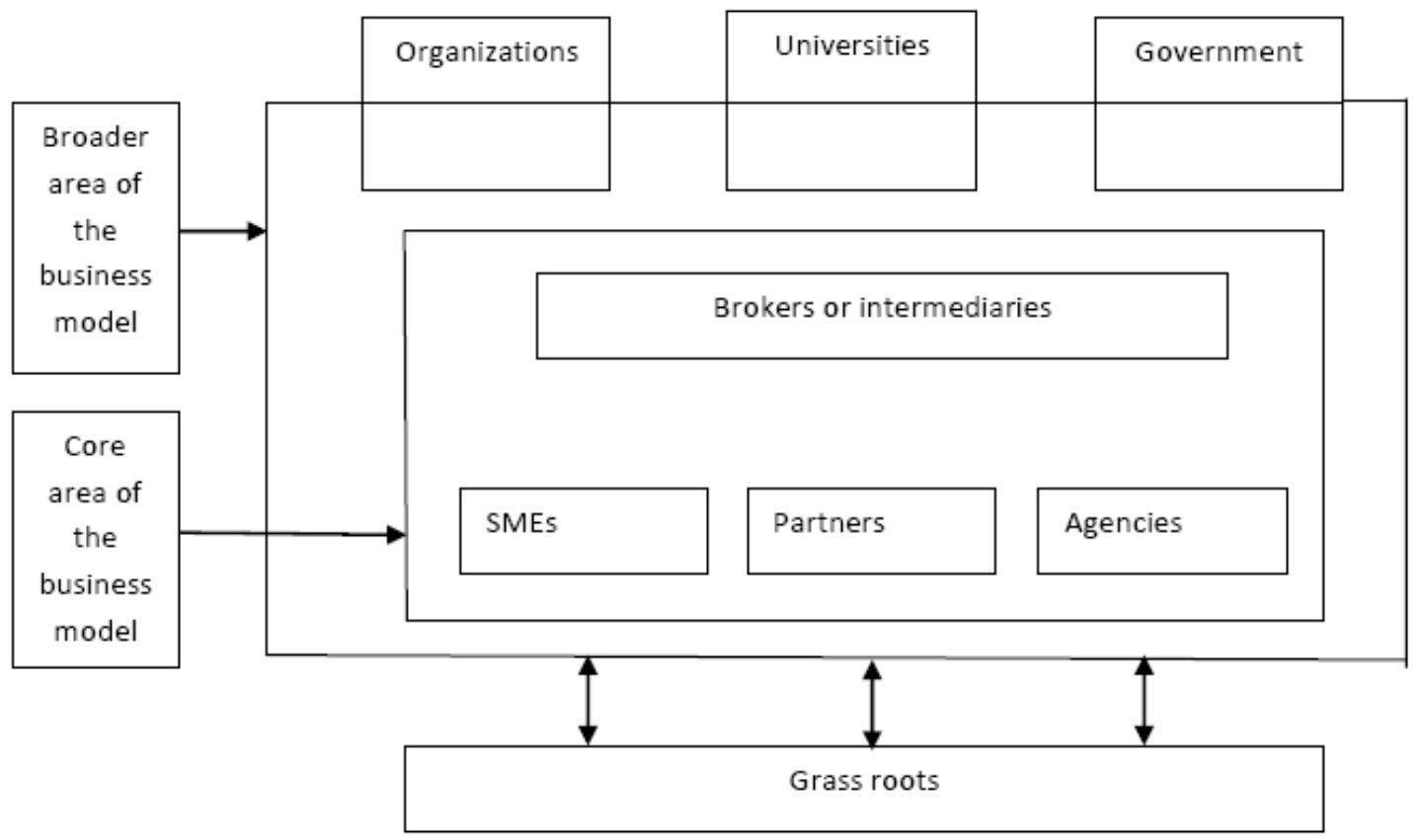

Figure-10: Building block of the proposed business model (Author)

The proposed business model (to be adopted in a few selected SMEs) emphasizes on two other tiers of relationship; among the core partners in the network and among the peripheral partners in the network. However, both the segments need not to be isolated from each other. Rather they may remain as active member of the entire community. Eventually, for sustained entrepreneurship the entire group must interact to the grass roots for effective dissemination of open innovation strategies promoting economic and value gain. 


\section{Recommendations and Future Discourses}

This has been observed that, in terms of improving their efficiency SMEs need to focus on improving their core competences. Furthermore, they need to cooperate with external partners to recompense for other competences and resources, especially in case of new product development. Therefore, recognizing the increasing importance of collaboration and partnership, new research may emerge as how to organize these external networks (Pullen et al., 2008).

Considering that the typical management challenges for SME managers that are quite different from those of managers of large enterprises, which would like to expedite the sustained growth engine in their company, would be an interesting uncharted area for future research (Chesbrough, Vanhaverbeke, \& West, 2006). However, the proximity of universities, research teams, brokering houses or intermediaries, large companies and lead users may play a key role in the deployment of open innovation in SMEs. Similarly, an optimized innovation policy fostering transactions among these innovation partners may also play a significant role in the longer run (De Vrande et al., 2008).

In terms of economic sustainability, cluster development is gaining importance in the economic policy debate. Despite, the globalization and evolution of information technologies, the phenomena of clusters, regional specialization of enterprises and institutions in common economic aspects are attracting potential researchers in this field (Ketels \& Sölvell, 2006). As Chesbrough $(2003,2006)$ mentioned, future research on open innovation should foresee innovative clusters around enterprises, and this research foresee that especially SMEs would be able to tap into the newest ideas needed to succeed in the contemporary market.

Future research in this aspect should also incorporate establishment of national and regional policies to promote open innovation among the SMEs, not limiting them to the administrative borders. SMEs within a region should open themselves to others if the product or service are not locally available. Similarly, dedicated tools to access unified information, recognize accepted patterns, follow management chain, reduce physical distance, and add economic value in terms of open innovation deserves further research discourses.

\section{Conclusions}

Innovation is seen as the development and commercialization of knowledge, transforming ideas and research into value-added products, processes or services (EEDA, 2008). Innovation, may lead to higher performance, but the process is not solely automatic. The process need to be focused more attentively to obtain the final outcome. Sometimes, many company's R\&D efforts remain unfocused. Money is wasted for "reinventing wheels" that others may have already rolled out. On the other hand, good ideas get stuck in developmental bottlenecks. Moreover, most of the time promising innovations never get to market because of flawed understanding of customer's needs, poor marketing and investment planning (Jaruzelski, Dehoff \& Bordia, 2006).

Furthermore, increasing global competition and rising research and development (R\&D) costs are pressurizing entrepreneurs to reach for new, more open modes of innovation, and to collaborate with external partners, whether suppliers, customers or universities or research centers, to keep ahead of the game and get new products or services to market before their competitors. At the same time, innovation is being generalized as users of products and services, both firms and individual consumers, are increasingly becoming involved within the innovation process by themselves (De Backer, 2008). Therefore, open innovation for SMEs has become a process of open, collaborative and networked model than the process of closed, classified and segmented model.

This research observes a journey of collaboration from closed boundaries to open but a networked paradigm, requires intensive interdisciplinary interactions among the core group of the business 
model (SMEs, partners, agencies and intermediaries). The more, the core group interacts with the outer peripheries of the business model upholding the value addition of innovation strategies, the fast the benefit of innovation will reach to the grass roots.

\section{References}

Australian Research Council. (n.d.). Glossary: Innovation. Retrieved from http://www.arc.gov.au/general/glossary.htm

Beije, P. (2005). Open innovation: The European challenge. A report submitted to Rotterdam School of Management / Erasmus University

Chesbrough, H. (2003). Open innovation: The new imperative for creating and profiting from technology. Boston, MA: Harvard Business School Press.

Chesbrough, H. (2006). Open business models: How to thrive in a new innovation landscape. Boston, MA: Harvard Business School Press.

Chesbrough, H., \& Rosenbloom, R. S. (2002). The role of the business model in capturing value from innovation: Evidence from Xerox Corporation's technology spin-off companies. Industrial and Corporate Change, 11(3), 529-555.

Chesbrough, H., Vanhaverbeke, W., \& West, J. (Eds.). (2006). Open innovation: Researching a new paradigm. London: Oxford University Press.

Christensen, J. F. (2007). Innovation concepts, processes and strategies. Presentation in PhD Course, Copenhagen Business School

Clark, T. R. \& Gottfredson, C. A. (2008). In search of learning agility: Assessing progress from 1957 to 2008. A report submitted to TRCLARK LLC.

CSR Europe. (2008a). The European Alliance for CSR Progress Review 2007: Making Europe a pole of excellence on CSR. European Commission, Brussels, 4 March 2008

CSR Europe. (2008b). R\&D Open innovation: Networks with SME. Open Innovation Network, 6 November 2008

De Backer, K. (2008). Open innovation in global networks. OECD Publishing

De Jong, J. P. J., Vanhaverbeke, W., Kalvet, T., \& Chesbrough, H. (2008). Policies for open innovation: Theory, framework and cases. Final report for a Research project funded by VISION Era-Net, Helsinki: Finland.

De Vrande, V. V., De Jong, J. P. J., Vanhaverbeke, W., \& De Rochemont, M. (2008). Open innovation in SMEs: Trends, motives and management challenges. A report published under the SCALES-initiative (SCientific AnaLysis of Entrepreneurship and SMEs), as part of the 'SMEs and Entrepreneurship programme' financed by the Netherlands Ministry of Economic Affairs, 2008.

Digital Strategy. (n.d.) Glossary of key terms: Innovation. Retrieved from http://www.digitalstrategy.govt.nz/Resources/Glossary-of-Key-Terms/

EEDA. (2008). ERDF Regional Workshops - Autumn 2008 Review Report. East of England Development Agency, UK.

EIRMA. (2004). Technology access for open innovation. Working Group Report WG63, Eirma: Paris.

Hadjimanolis, A. (1999). Barriers to innovation for SMEs in a small less developed country (Cyprus). Technovation, 19, 561-570.

Hanna, V., \& Walsh, K. (2002). Small firm networks: A successful approach to innovation? R\&D Management, 32(3), 201-207.

Höllmüller, C. (2008). Chances for small and medium-sized enterprises (SME) in international innovation networks. A presentation at the Innovation Day Swiss Texnet, Dübendorf, 28 August 2008. 


\section{Open Innovation in SMEs}

Huston, L. \& Sakkab, N. (2006). P\&G's new innovation model. An excerpt from Connect and develop: Inside Procter \& Gamble's new model for innovation. Harvard Business Review, 84(3), March.

Jaruzelski, B., Dehoff, K. \& Bordia, R. (2006). Smart spenders: The global innovation 1000. Strategy+Business, 45, 46-61.

Kaufmann, A., \& Tödtling, F. (2002). How effective is innovation support for SMEs? An analysis of the region of upper Austria. Technovation, 22(3), 147-159.

Ketels, C., \& Sölvell, Ö. (2006). The Baltic Sea Region - Top of Europe in global competition. State of the Region Report, Baltic Development Forum, Denmark.

Lichtenthaler, U., \& Ernst, H. (2009). Opening up the innovation process: The role of technology aggressiveness. $R \& D$ Management, 39(1), 38-54.

Lindermann, N., Valcareel, S., Schaarschmidt, M., \& Von Kortzfleisch, H. (2009). SME 2.0: Roadmap towards Web 2.0-based open innovation in SME-network- A case study based research framework. In G. Dhillon, B. C. Stahl, \& R. Baskerville. (Eds.). CreativeSME2009. IFIP International Federation for Information Processing, IFIP AICT 301, pp. 28-41.

Michael, S. C., \& Palandjian, T. P. (2004). Organizational learning in new product introductions. Journal of Product Innovation Management, 21, 268-276.

OECD. (2000). OECD science technology and industry outlook 2000. OECD, Paris

OECD. (2006). The Athens action plans for removing barriers to SME access to international markets. Adopted at the OECD-APEC Global Conference in Athens, on 8 November 2006, OECD Report, Paris.

Piatier, A., (1984). Barriers to innovation. London: Frances Pinter.

Pourdehnad, J. (2007). Idealized design - An "open innovation" process. A presentation from the annual W. Edwards Deming Annual Conference, Purdue University, West Lafayette, Indiana, October 2007.

Pullen, A., De Weerd-Nederhof, P., Groen, A., \& Fisscher, O. (2008). Configurations of external SME characteristics to explain differences in innovation performance. Proceedings of the High Technology Small Firms Conference 2008: Twente University, Netherlands.

Renaud, P. (2008). Open innovation at Oseo innovation: Example of the Passerelle Programme. A presentation at the OECD Business Symposium on Open Innovation in Global Networks, Copenhagen, 25-26 February, 2008.

Rush, H., \& Bessant, J. (1992). Revolution in three-quarter time: Lessons from the diffusion of advanced manufacturing technologies. Technology Analysis and Strategic Management, 4(1), 3-19.

Shorthouse, S. (2008). Innovation and technology transfer. A presentation from the International Conference DISTRICT 2008. International Conference Centre, Dresden, 29 May 2008.

West, J., \& Gallagher, S. (2006). Open innovation: The paradox of firm investment in open source software. $R \& D$ Management Special Issue on "Opening-up the innovation process", 36,3 (June).

West, J., Vanhaverbeke, W., \& Chesbrough, H. (2006). Open innovation: A research agenda. In H. Chesbrough, W. Vanhaverbeke, \& J. West (Eds.), Open innovation: Researching a new paradigm. Oxford University Press.

Wikipedia. (n.d.) Open innovation. Retrieved from http://en.wikipedia.org/wiki/Open_Innovation

Wolf, A. (2005). smE MPOWER Outlook: Empowering SMEs for long-term research interest and increased participation in EU RTD activities! Retrieved March 15, 2009 from http://www.smempower.net/Presentations/11\%20Andreas\%20Wolf\%20on\%20smE-MPOWER-Community.pdf 


\section{Biographies}

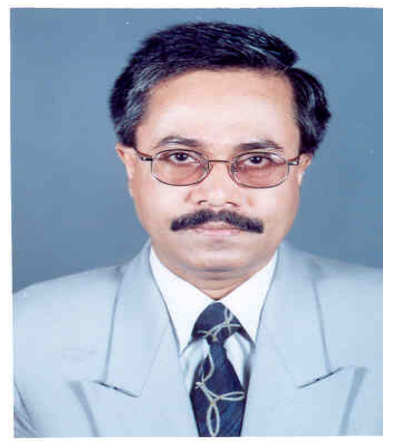

Engr. Md. Hakikur Rahman, PhD. an academic over 25 years has served leading education institutes and established various ICT projects funded by ADB, UNDP and World Bank in Bangladesh. He is currently serving as a Post Doctorate Researcher at the University of Minho, Portugal. He has written and edited over 10 books on computer education in ICT, education and research. Graduating from the Bangladesh University of Engineering and Technology in 1981, he has done his Master's of Engineering from the American University of Beirut in 1986 and completed his $\mathrm{PhD}$ in Computer Engineering from the Ansted University, BVI, UK in 2001.

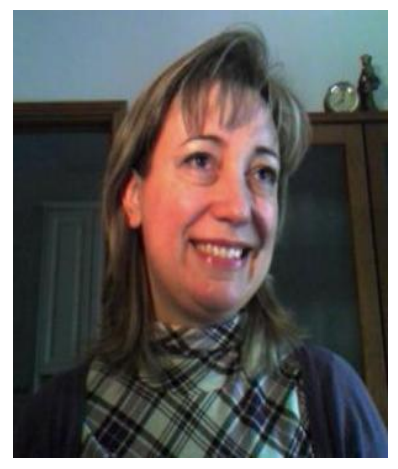

Isabel Maria Pinto Ramos has a doctorate degree in Information Technologies and Systems, specialization in Information Systems Engineering and Management (2001) and a master degree in Informatics for management. She is an Assistant Professor in the Information Systems Department of the Minho University, Portugal and Chair of the Information Systems Master Programs of the University. Dr. Ramos is Associate Editor of the International Journal of Technology and Human Interaction and member of the editorial board of Enterprise Information Systems. She is Secretary of the Technical Committee 8 (Information Systems) of IFIP - International Federation for Information Systems and awarded with the IFIP Outstanding Service Award in 2009. She is author and co-author of two books and more than 4 dozens of scientific and technical papers.

i There is no single agreed definition of a SME. A variety of definitions are applied among OECD and APEC economies, and employee number is not the sole defined criterion. SMEs are considered to be non-subsidiary, independent firms which employ less than a given number of employees. 